\title{
Challenges for Corporate Foresight: Towards Strategic Prospective Through Scenario Thinking
}

John Ratcliffe

Technological University Dublin, john.ratcliffe@tudublin.ie

Follow this and additional works at: https://arrow.tudublin.ie/futuresaccon

Part of the Business Administration, Management, and Operations Commons

\section{Recommended Citation}

Ratcliffe, J.: Challenges for corporate foresight: towards strategic prospective through scenario thinking. 7th Annual International Conference Foresight Management in Corporations and Public Organisations New Visions for Sustainability. Helsinki, Finland, 10th June, 2005.

This Conference Paper is brought to you for free and open access by the Futures Academy at ARROW@TU Dublin. It has been accepted for inclusion in Conference papers by an authorized administrator of ARROW@TU Dublin. For more information, please contact arrow.admin@tudublin.ie, aisling.coyne@tudublin.ie, gerard.connolly@tudublin.ie.

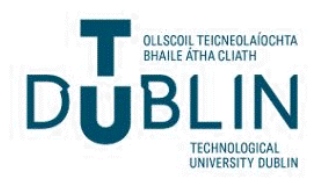




\author{
$7^{\text {th }}$ Annual International Conference \\ FORESIGHT MANAGEMENT IN \\ CORPORATIONS AND PUBLIC ORGANISATIONS \\ NEW VISIONS FOR SUSTAINABILITY \\ " Challenges for Corporate Foresight: \\ Towards Strategic Prospective Through Scenario Thinking" \\ KEYNOTE ADDRESS \\ By \\ Professor John Ratcliffe \\ Director: Dublin Institute of Technology \\ Chairman: The Futures Academy
}

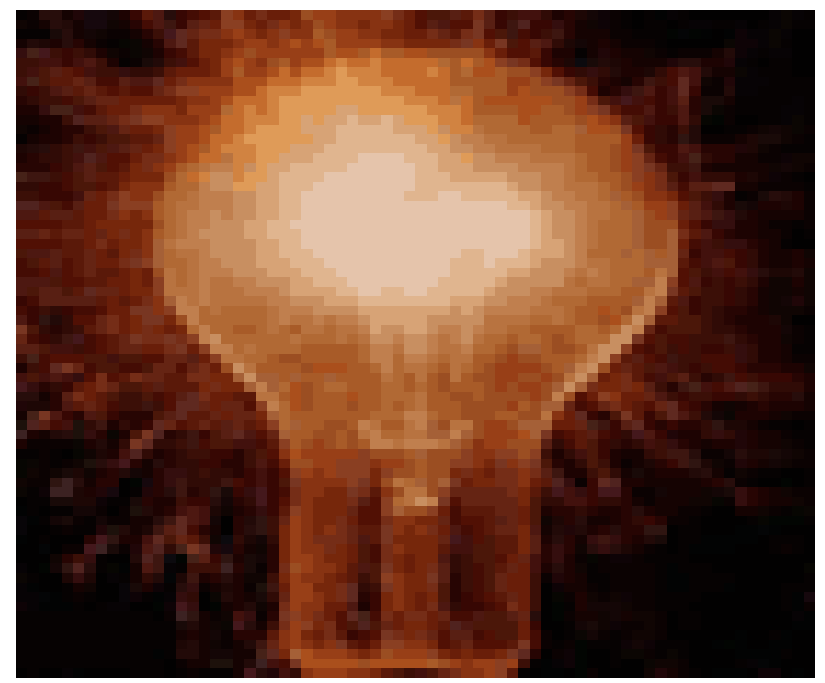

Helsinki, Finland

Friday $10^{\text {th }}$ June 2005 


\section{" CHALLENGES FOR CORPORATE FORESIGHT: Towards Strategic Prospective Through Scenario Thinking”}

\section{CONTEXT}

\section{The Transformation}

Every few hundred years there occurs, in Western history, a sharp 'transformation'. Within a few short decades, a society rearranges itself - its worldview; its basic values; its social and political structure; its arts; its key institutions. Fifty years later there is a new world. The birth of the European city in the thirteenth century; Gutenburg's invention in 1455 of printing with movable type; and the perfection of the steam engine along with the American Revolution and Adam Smith's 'Wealth of Nations', all in the last quarter of the eighteenth century, mark three such transformations [Drucker, 1993].

We currently live in just such a period of transformation. It is creating the 'Post Capitalist Society'. In some areas, basic shifts in society and structure have already happened. With virtual certainty it can be said that the new society will be nonsocialist, post-capitalist, discontinuous and organisationally pluralist. Information will lead to knowledge, and hopefully knowledge to wisdom. Regulation, likewise, will give way to awareness, and awareness in turn to responsibility. The one thing we can be sure of is that the world that will emerge from the present rearrangement of values, of beliefs, of social and economic structures, of political concepts and systems, indeed of world views, will all be different from anything anyone today imagines [ibid]. Everything is in flux, which is why it is also the time to shape the future now. This is the 'grand challenge' for society at large - and for corporations in particular.

\section{A New Mindset}

A new mindset is required by corporate organisations to anticipate and prepare for the future. A mindset that embraces individualism, collaboration and innovation. A mindset that addresses societal and environmental, as well as economic, imperatives. Above all, however, a mindset that can tackle complexity, uncertainty and change.

In other words, corporate management, in the post-capitalist era demands a total strategic commitment based, as Tom Peters [1988] would say:

"on entirely new ways of thinking about organisations".

This implies a mindset that is oriented to process rather than to structure; that is ecologically driven rather than hierarchically driven; that is value-added rather than competitive; that is holistic rather than functional; and that is collaborative and innovative rather than adversarial and derivative.

A futures orientation, with strong foresighting capability and capacity, founded on flexible and adaptable systems, is the secret of success. 


\section{The Need for Futures Thinking}

To create the future one must first be capable of imagining it. Not predicting, not planning, not forecasting - imagining. Preparing an organisation to anticipate that it could face a number of environments that are fundamentally different from the present is a radical departure from standard practice for most. But by learning to develop and use methods and techniques drawn from the 'futures field', organisations can take actions to make a desirable future occur, quickly adapt to unfavourable environments, and efficiently implement strategies that will succeed in many different social and market conditions.

Here, I fear, Foresight, as a field is failing. It has fallen into the hands of bureaucrats, technocrats and, forgive me, academics. Whilst there is a clear need for structures, organisation, rigour, experts and information; there is an overriding need for vision, imagination, creativity and judgement. The exploratory and questioning spirit of foresight is in grave danger of being quashed by the dreary and disheartening machinations of governance, civic and corporate, and the pedantry and procrastination of academe. The qualitative, subjective, and behavioural dimensions of foresighting, are all too frequently overshadowed by the quantitative, technological and empirical.

Furthermore, I would argue that there should be three distinct phases in any 'futures' exercise - Divergence, Emergence, and Convergence (see exhibit 1) - and that far too many foresighting studies place too much emphasis on the second stage - Emergence - and too little on the first and third - Divergence and Convergence. Because of this, there is insufficient difference now between many so called foresighting programmes and most conventional strategic surveys, analyses and plans. The quest and zest have gone!

\section{Conceptual Approach}

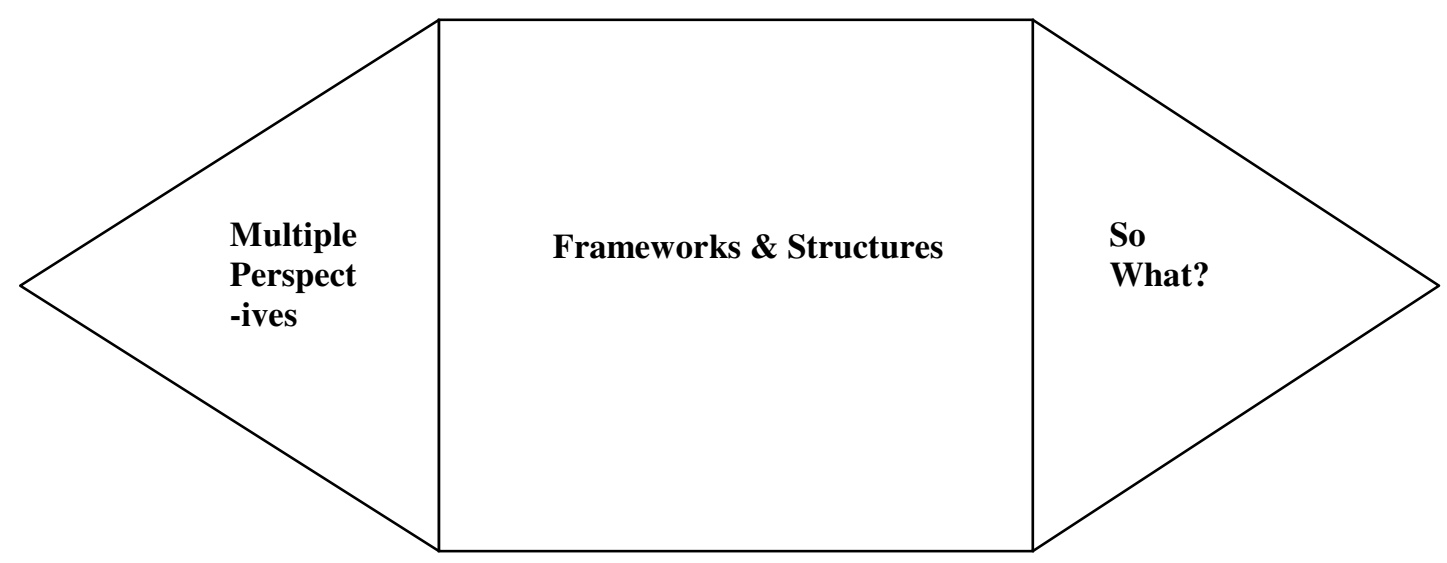

Emergence

Divergence

Convergence

Exhibit 1. Outsights 
For this reason, as a scenario planner of long-standing, I have also become increasingly attracted to the Prospective method. And, at the Futures Academy, DIT, we have developed, tested and tried a futures approach called 'Strategic Prospective Through Scenarios Thinking' (see exhibit 2) which combines the French prospective methodology with Anglo-American scenario planning techniques.

It is worth recalling that Gaston Berger, one of the founders of the prospective school over half-a-century ago, distinguished the main principals of the approach as being [Roubelat, 1997]:

- to look far away, as prospective is a long-term activity:

a to look breadthways, in order to examine interactions;

a to look in-depth, so as to become aware of the most important trends and issues;

a to take risks, because new adventures can lead to the change of long-term plans; and

- to take care of humanity, as prospective should fundamentally be concerned with implications for people.

\title{
The Scenario Matrix
}

\author{
HIGHER UNCERTAINTY
}

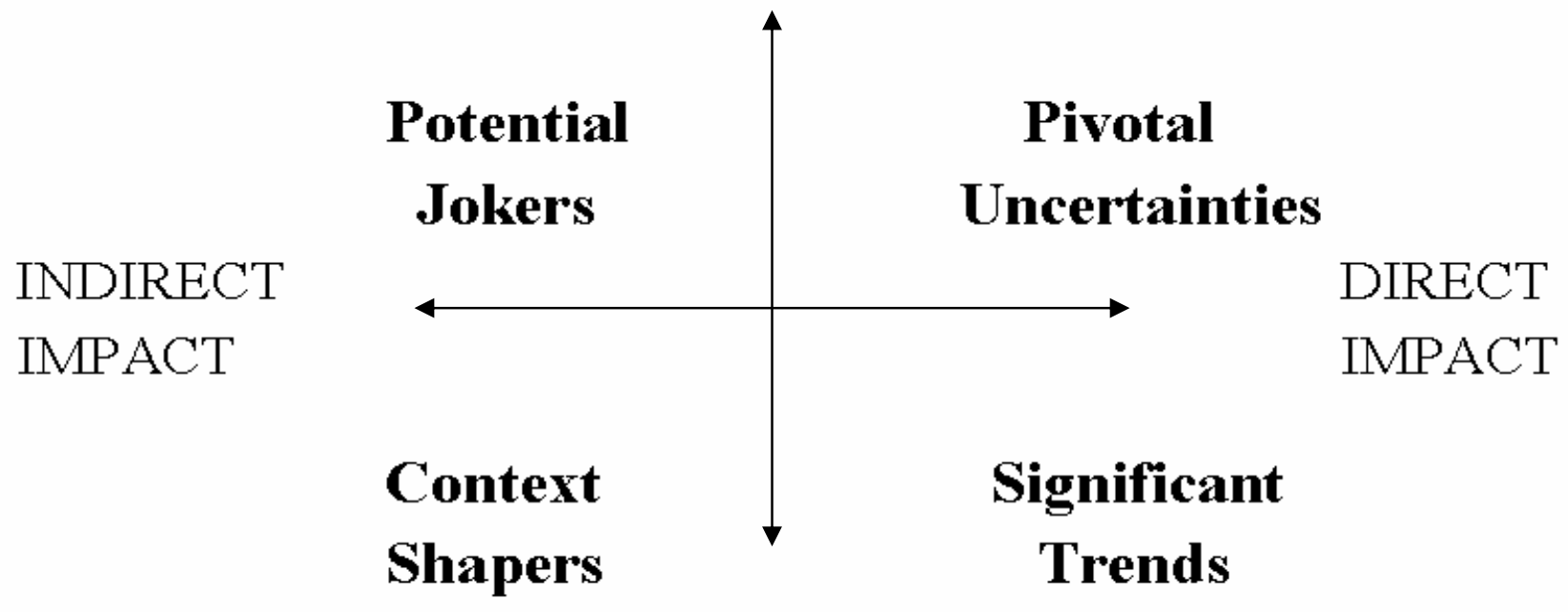

LOWER UNCERTAINTY

Exhibit 2. The Scenario Matrix 


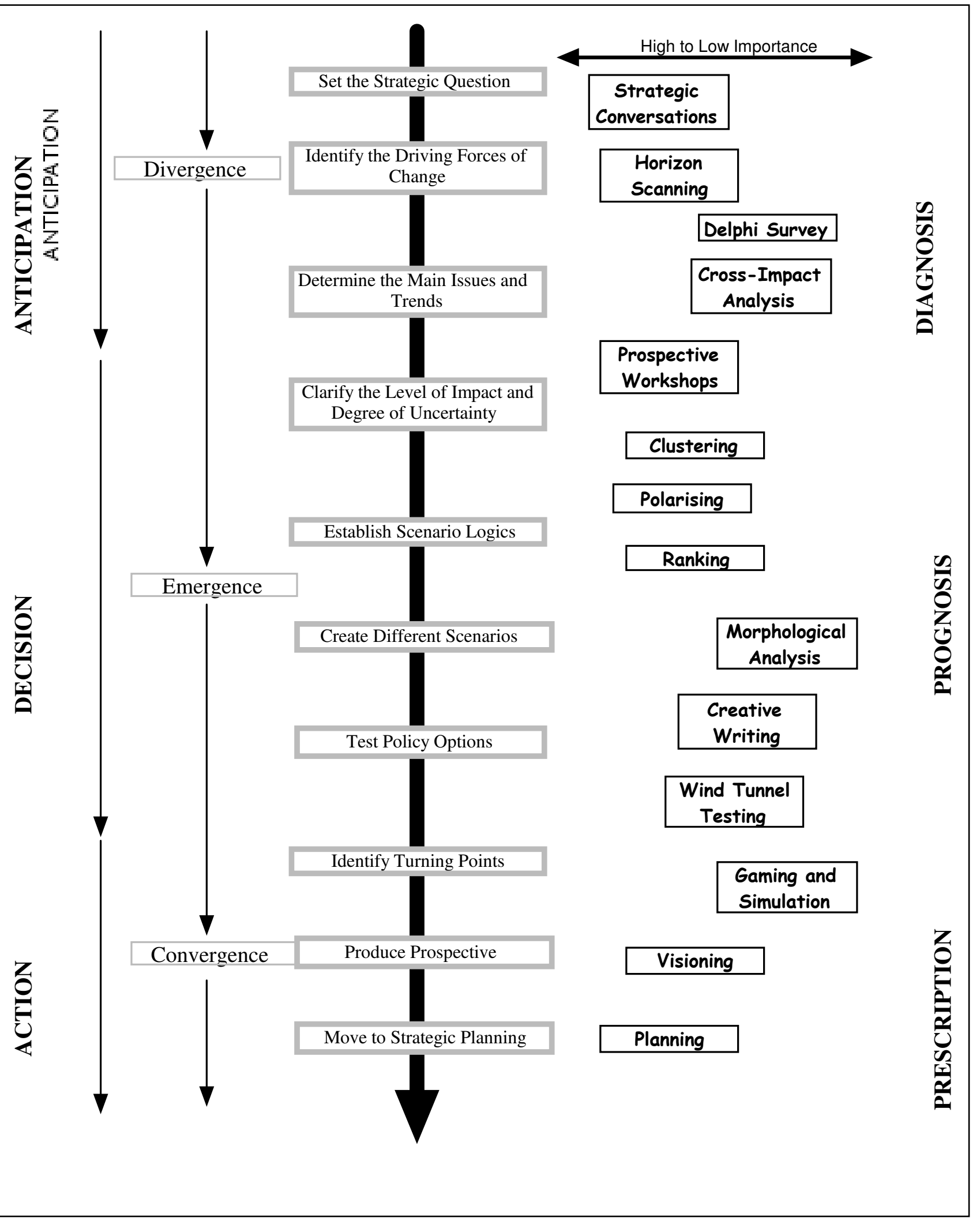

Exhibit 3. "Prospective through Scenarios'

Source: Ratcliffe and Sirr (2003) The Futures Academy 
Within this prospective, scenarios provide powerful tools for strategic policy analysis, especially where policy-makers have fragmented, unstructured and biased information. They provide a comprehensive, clear and accessible insight into how policy options might play out in various different futures.

What then are the major challenges facing the corporate world in adopting a futures oriented approach, whether by way of foresight or prospective? For the purposes of this address I have grouped them into five formative fields.

1. Fostering a CULTURE of Foresight

2. Envisioning CHANGE

3. Exploring CREATIVITY

4. COMMUNICATING Futures

5. CHAMPIONING Prospective

For each of these fields three key action areas have been identified.

\section{FOSTERING A CULTURE OF FORESIGHT}

Moving from traditional planning to futures and foresight-based strategic planning requires first and foremost a transformation of corporate culture. Many, probably most, of the problems of introducing foresighting into an organisation, stem from a failure to recognise the magnitude and duration of the implementation effort that is required to use a futures oriented approach to change management assumptions, attitudes and aspirations. Most corporate cultures, moreover, are still heavily biased towards quantitative analysis, whereas a futures approach, especially one using scenarios, is primarily qualitative.

The three key action areas are:

a Core Values

- Civic Responsibility

口 Credibility Through Scanning

\section{Core Values}

A major shift is for a corporation to move from respecting 'knowing' to cherishing 'not knowing'. Good managers, it is all too often said, know where they are going and how to get there. Futures, foresight and scenarios, by contrast, confront us with the need to admit that we do not, and cannot, know much of what lies ahead. There is an obvious need, therefore, to change the system so that managers routinely consider alternatives - futures, strategies and tactics - before making a decision. Indeed, this process should be mandatory and automatic, a core value, not merely voluntary and desirable.

A distinction can be made between three different kinds of values attached to different levels of organisational experience [Limerick et al, 2002]. These are: 
- Transcendental Values; that hold true, above all others, whatever the field and the situation, and are closely associated with the identity and culture of the organisation. They tend to define what kind of people the firm would like to be.

- Strategic Values; those directly related to the mission and logic of the organisation, such as the commitment to market share, growth or technical excellence. They define not what kind of people the firm are, but what they do.

- Operational Values; these are intimately related to the daily operations of the different parts of the organisation. They define how things are done.

No one knows the end from the beginning, but a constant theme which plays throughout successful corporations is that they have been led by a broad, overarching, shared vision, underpinned by a set of collective values enabling them to become action-learning communities. The prospective process provides a means by which this shared vision is shaped, and scenario thinking helps create a culture that prepares all concerned to be agile and flexible amid changing forces and priorities - whilst adhering to core values.

\section{Civic Responsibility}

No longer is it possible for corporations to go about their business, quietly or otherwise, telling no lies and breaking no laws, selling things that people want, and making money. That world has gone. Today, all companies, but especially big ones are enjoined from every side to worry less about profits and be socially responsible instead. Thus, companies at every opportunity now pay elaborate obeisance to the principles of corporate social responsibility (CSR) [Economist, 2005]. Indeed, it has been stated that arguably the single most important issue of the $21^{\text {st }}$ century is the power of large corporations to shape the future of the planet [Collier \& Fuller, 2005]. My own view echos, in its timorous way, that of Jack Welch, who, when chairman of general Electric, stated:

"I've always believed that the greatest contribution a business can
make to society was its own success, which is the fountainhead of
jobs, taxes, and spending in the community. I still believe that - but I
don't think that is enough anymore. And I don't believe even
generous financial philanthropy on top of that prosperity is enough.
In these times companies cannot remain aloof and prosperous while
surrounding communities decline and decay."

Generally, there can be little disagreement that corporations worldwide need to develop a profound sense of responsibility. And, in this context, it is argued that responsibility without foresight is blind, but more critically, foresight without responsibility is dangerous [ibid]. Interestingly, moreover, in examining the degree to which the links between responsibility and foresight are being made by companies in their reporting on CSR it is apparent that the attitudes of managers to time and the future is exactly the opposite of what is needed. Instead of thinking about the risks 
created by the organisation for the future of society, they anticipate the future risks in society and its present effects on the corporation [Fuller \& Tilley, 2005].

The clear challenge to corporations is, that whilst integrity in business has traditionally meant being honest, upright and ethical, that is no longer sufficient. Globalisation, and all that goes with it, is forcing companies to add another fundamental quality - integration with society. Corporations must anticipate and respond directly to the demands of public opinion rather than waiting for government intervention, mediation and regulation to compel them into action. In short, corporations must examine their operations from a long-term prospective in a civic context.

\section{Credibility Through Scanning}

In building their corporate strategies, it has been suggested that most companies [Kim \& Mauborgne, 2005]:

- Define their industry similarly and focus on being the best within it.

- Look at their industries through the lens of generally accepted strategic groups, and strive to stand out in the strategic group in which they play.

- Focus on the same buyer group.

a Define the scope of the products and services offered by their industry similarly.

- Accept their industry's functional or emotional orientation.

a Focus on the same point in time - and often on current competitive threats - in formulating policy.

The more that companies share this conventional wisdom about how they compete, the argument runs, the greater the competitive convergence among them. The challenge is to break-out of this way of thinking. And the answer, put very simply, if not simplistically, is systematically to conduct continual scanning across alternative industries, across strategic groups within industries, across the chain of buyers, across complementary product and service offerings, across the functional-emotional orientation of an industry, and even across time [ibid]. Strategy after all, should not be about imitation, but about responding to weak signals, and an important part of foresighting for every company is to develop scenarios of new business models. For managers, who, by creating a culture of foresight, can expand their imaginations to see a wider range of possible futures will be in a much better position to take advantage of the unexpected opportunities that will surely come along.

\section{ENVISIONING CHANGE}

Experience teaches us that some future events or potential surprises do seem to be predictable; or at least expectations have some chance of occurring. So what are the distinguishing traits of a predictable surprise? Some of the most common, and perhaps the most obvious, have been offered as follows [Bazerman \& Watkins, 2004]: 
a Leaders know a problem exists, and that it will not solve itself.

- Organisational members recognise that a problem is getting worse over time.

a Fixing the problem incurs significant costs now, with benefits delayed into the future.

- Expenditure now avoids a cost in the future, but the reward will largely be unrecognised.

- There is a tendency for decision-makers to maintain the status quo.

- A small minority who benefit from inaction are motivated to subvert action for change.

How can these be addressed? Well, foresighting, and in particular scenario planning, can be a major factor for change by enlisting the people in an organisation with the power to act; creating wide awareness of external imperatives for change; guiding the formulation of operational plans; and creating coherence in management action through the development of consensus in the management team. In addition, scenarios can make a contribution at leadership level through the diffusion of political tension around strategic issues [van der Heijden, 1996].

Three key action areas are:

- Chaos and Complexity

a Cognitive Roots

口 Capacity and Capability

\section{Chaos and Complexity}

Comprehending complexity is critical to corporate policy-making and commercial success. Virtually all business organisations are 'complex adaptive systems', popularly referred to as chaotic, and have several central characteristics which have a direct bearing on foresighting and strategic planning. These are [Zeisler \& Harris, 2000]:

a Complex adaptive systems have limited predictably. Not no predictability, just limited.

- Small events, epitomised by weak signals, and often hidden by the surrounding noise, can cause great change.

- The most prolific breeding ground for innovation in complex adaptive systems is an area known as 'bounded instability', otherwise known as the edge of chaos.

To enable an organisation to flourish in a world of complexity and within the edge of chaos five dimensions of the necessary business environments have been identified [Ekvall \& Tångenerg - Andersson, 1986]:

- Challenge; the level of involvement that exists for members of an enterprise in carrying out their roles responsibilities,

- Freedom; the degree of independence exercised by individuals within the bounds and context of the organisation's goals and mission.

- Idea Time; the amount of time individuals devote to scanning horizons, detecting weak signals, creating ideas and acting on them. 
- Risk-taking; the level of tolerance for uncertainty and ambiguous outcomes, and the willingness to try the unproven and new.

- Idea Support; the extent to which ideas are solicited and treated.

Corporations, especially large ones, must appreciate that success at the edge-of-chaos is not about resources but about mind-set. Their leaders must have the will to act quickly on new signals and respond positively to the unexpected.

\section{Cognitive Roots}

We are all now aware that human judgement and decision-making deviates from rationality. Five cognitive biases have been detected that mitigate against change in the face of uncertainty [Bazerman \& Watkins, op cit]:

a The harbouring of positive illusions which lead to the conclusion that a problem does not exist, or it is not serious.

- Interpreting events in an egocentric manner, so that credit and blame are allocated in a self-serving way.

- Overly discounting the future ${ }_{2}$ and reducing the courage to act now on what seems a distant problem.

- Refusing to confront unpalatable choices, and avoiding significant unpopular action to bring about a greater long-term good.

a Reluctance to invest in dramatic action without personal experience and vivid data regarding the issue at hand.

These biases or errors often work together. Identifying them by gaining greater understanding of the limits of human cognition, and allowing corporate leaders to create structures which reduce the damage they cause, should be part and parcel of effective foresighting and fruitful scenarios.

\section{Capacity and Capability}

Why do organisations fail? There are, of course, a multitude of reasons according to circumstance, but in the context of envisioning change the following are the most frequently reported.

- Believing what we want to believe, and failing to pay attention to the early signs of change.

- Looking at the parts of the organisation and its fields of operation rather than the whole.

- Submitting to the tyranny of the present, and colouring our view of the future with our most recent experience.

- Framing the problem, or the opportunity, incorrectly and asking the wrong questions.

a Overestimating our ability to control the future.

a Relying too much on the opinions of experts, who tend to be like-minded and inter-connected, and too little on the value of 'innocent eyes'.

a Ignoring the redefinition of terms, units, services and products.

a Disregarding both developmental and substitution effects.

a Getting the timing wrong. 
- Forgetting that sometimes it takes a long time to get a good idea accepted.

- Neglecting to recognise "what we don't know we don't know" [Heinzen, 1999].

The list is almost endless. Indeed, what is known as 'the Sharpbenders research' [Gringer et $a_{2}$ 1999] highlights the key causes of relative decline in corporations in five categories as follows:

- Adverse development in market demand or increased competition

a High cost structure

- Poor financial controls

a Failure of big projects

口 Acquisition problems

The strategic reasons for failure identified in the Sharpbenders research included:

- A lack of recognisable strategies in such areas as functional policies, corporate strategy and environmental monitoring.

- Poor expectations or timing of responses to developments such as declining market demand or increasing competition.

- Inappropriate risk-taking, in terms of projects that were too large in relation to the size of the organisation.

At the heart of it, however, there is frequently a lack of exploration of the wider environment and poor understanding of how it is impacting upon the market and the business, and their respective needs and value systems [van der Heijden, 2002]. Scenario thinking helps make organisations adaptive learners better capable of developing a deeper perspective of their long-term business environment.

\section{CREATIVITY EXPLORATION}

Arthur Koestler [1964] argued that creativity often springs from the unexpected juxtaposition of realms of thought not often combined. More recently, such multidisciplinary creativity has been called 'intersectional innovation', or more evocatively, The Medici Effect [Johansson, 2004]. Intersection innovations are radical and change the world, the business environment and the market, in leaps along new directions. They can happen, however, in large and small ways, but share the following characteristics [ibid]:

- They are surprising and fascinating.

- They open up entirely new fields.

- They provide a space for a person, team or company to call its own.

a They generate followers, which means the creators can become leaders.

a They provide a source of directional innovation for years or decades to come.

- They can affect the world in unprecedented ways.

Creativity of this kind will more usually be found where different realms of expertise find themselves thinking together. The modern research university, or business management consultancy for that matter, with their departmental walls separating 
different specialities, are scarcely the vehicles for driving such creativity. Indeed, one could hardly do worse. Foresighting, and most especially scenario workshops, whose participants are selected precisely for the diversity of their expertise, offers a far richer medium for the cultivation of creative ideas [Ogilvy, 2002].

Three key action areas are:

- Conceptualisation

- Competitive Advantage

a Collaboration and Concertation

\section{Conceptualisation}

All organisations come into existence as an act of vision. This vision, or strategic intent, looks to the future and establishes a sense of direction to an organisation, offering a road-map of what lies ahead and generating enthusiasm, focusing attention and instilling confidence. It acts as a nucleus about which may form the grand strategy that goes from identity, through configuration, to action. The vision, thus, represents a future preferred state of the organisation, and will often incorporate an image of a desirable mission, values and even hoped- for alignment of strategy, structure, and culture [Limerick, et al, op cit].

The term 'vision', however, is a concept that has become flabby and defamed. The challenge is to construct, through foresighting and scenarios thinking a conceptual framework carefully to define vision, add clarity and bring rigour to the vague and fuzzy concepts swirling around that trendy term. In this, it has been contended that [Collins \& Parra, 1996]:

"A well-conceived vision consists of two major components: core ideology and envisioned future. Core ideology, the yin in our scheme, defines what we stand for and why we exist. Yin is unchanging, and complements yang, the environmental future"

Conceptualisation through foresight and scenarios also involves the setting of a 'mission'. Mission, in a sense, however, is the ongoing established vision of the organisation, but perhaps more directed, having to do with the purpose of the organisation. Perceptively, the link between vision and mission, or meaning and purpose, has been called the 'psychic centre' of an organisation comprising its most cherished beliefs, true values and preferred direction [Harmon \& Jacobs, 1985].

\section{Competitive Advantage}

Much has been researched and written about 'competitive advantage', and much more is likely to come, but in the context of exploring corporate creativity within the field of foresight, and by the use of scenarios, the recent text by W. Chan Kim and Renée Maulborgne [2005] upends traditional strategic thinking. The gist of their thesis, colourfully branded Blue Ocean Strategy, is: 
- Do not compete in existing market space. Instead, create uncontested market space.

a Do not seek to beat the competition. Instead, make the competition irrelevant.

- Do not exploit existing demand. Instead create and capture new demand.

a Do not make the value/cost trade-off. Instead break the value/cost trade-off.

- Do not align the whole system of a company's activities with its strategic choice of differentiation or low cost. Instead align the whole system of a company's activities in pursuit of both differentiation and low cost.

They establish 'six principles' by which this can be achieved. These can be briefly summarised as [ibid]:

1. Reconstruct market boundaries [search risk].

2. Focus on the big picture, not the numbers [planning risk].

3. Reach beyond existing demand [scale risk].

4. Get the strategic sequence right [business model risk].

5. Overcome key organisational hurdles [organisational risk].

6. Build execution into strategy [management risk].

The cornerstone of this Blue Ocean Strategy is called 'value innovation' - creating powerful leaps in value for both company and the customers, rendering rivals obsolete and unleashing fresh demand - and the most obvious methodology for implementing it would seem to be some form of Strategic Prospective Through Scenario Thinking approach. [Unsurprisingly perhaps!]

\section{Collaboration and Concertation}

Over the past couple of decades, there has dawned a new age of 'collaborative individualism' - reflecting an era of the empowerment of the individual, and paradoxically, an era in which the interdependence between individuals has grown even stronger. The concept is best described as follows [Limerick, et al, op cit]:

"Collaborative individualism is a worldview held by a growing number of people in Western society. In some organisations it is a management ideology - a view held by the dominant coalition in the organisation. In others it is a complete culture, a shared world of meaning, with its own patterns of values and characteristic systems of action. Collaborative individualism is the dominant culture of network organisations: it stresses the need for individuals to work together with others towards a common vision and mission. But it also stresses their emancipation, their freedom to reject hierarchical organisation and bureaucratic rules"

The significance of such change is that the five essential elements of foresight [FOREN, 2001] - anticipation, participation, networking, vision and action - come to the fore in corporate strategic policy-making. Further, the most important aspects of foresight process, précised below [Irvine \& Martin, 1984], are those most demanded by collaborative business operation in modern corporate affairs. 
a Communication between parties concerned.

a Concentration on the longer term.

- Co-ordination of research and development.

- Consensus created on future directions and policies.

a Commitment generated among those responsible for implementation of policy.

On top of all this, three powerful forces - the movement of people, the convergence of science, and the leap of computation - are producing more 'intersections' than ever, requiring greater collaborative effort and increased connectivity of thought and action. This challenges foresight itself to move to a higher plane of 'concertation'.

\section{COMMUNICATING FUTURES}

Communications are clearly an essential part of strategic planning and policy implementation. If major changes in corporate culture are to take root, participants at every level must comprehend, define, clarify and communicate the nature and implications of those changes. And communications, of course, must fit the needs of the various internal and external audiences. Thus, 'communicability' is a vital characteristic that companies must build into their visioning, foresight and scenario processes. To change the mind-set of planners, executives, and operatives for that matter, the leaders of change in a corporation must first capture and hold their attention. They must ensure a continuing interaction of interest, ideas, and information throughout the organisation.

Three key action areas are:

- Conversation

口 Connectivity

\ Composition

\section{Conversation}

The future cannot be measured, but it can be foreseen. Foresight, however, is largely a matter of conjecture, and at the heart of conjecture lies conversation. Organisations, in fact, are essentially networks of personal interconnections based on conversation. Thus, in enabling complex adaptive organisations to look ahead, conversation, in one form or another, becomes a key component of strategic planning.

The art of 'strategic conversation' was first described by Kees van der Heijden [1996] when defining the continuing process of dialectic that takes place within an organisation as part of scenario planning exercise - and beyond - to form a shared mental model of the organisation, its goals, and the way in which it sets out to achieve them. There are many, interrelated, reasons for conducting strategic conversations, which have usefully been summarised as follows [Ratcliffe, 2002]:

Establishing the goals and objectives of the organisation.

- Comprehending the mental models of the decision makers.

- Bringing to the surface trend-breaking developments.

- Correcting institutional myopia. 
- Recognising fresh external signals of prospective change.

- Eliciting strategic insights and intuitions.

a Discovering the concerns of 'key players' about the future

a Identifying burning questions of the moment.

a Confirming issues and trends.

- Assisting in undertaking predictability, impact and uncertainty.

- Starting to form a strategic vision.

- Helping to construct a set of scenario logics.

- Capturing a range of perspectives.

- Tackling and reducing complexity.

- Determining competitive advantage and distinct competencies.

- Exploring uncontested market space.

- Committing decision-makers to the foresight and scenario planning process.

a Diagnosing difficult decisions or awkward people that might hamper the process and defusing them.

a Setting the strategic agenda.

The underlying purpose, however, is that strategic conversation leads to action, having investigated the 'hows' and the 'whys', as well as the 'whats' of experience.

\section{Connectivity}

Connectivity has been described as a critical driver of business futures [Altherton, 2005]. The very term 'only connect' was the constant admonition of the great English novelist EM Forster, and has always been the hallmark of genius - a Darwin, a Bohr or an Einstein. But connectivity is learnable. It requires, nevertheless, a methodology, and, unsurprisingly, foresighting through scenarios is particularly well-suited to creating a connected learning organisation.

One of the main challenges to achieving greater connectivity is breaking down conventional barriers within and around corporations. Some of the ways in which this can be done are [Johansson, op cit]:

- Exposure to a diverse range of cultures - ethnic, class, generational, professional, or organisational.

- Learn differently - interdisciplinary, cross-disciplinary, multi-disciplinary and transdisciplinary.

- Reverse assumptions - to free the mind from preconceived notions.

- Try adopting different perspectives - Leonardo da Vinci believed in viewing things from three stances, and 'triangulation' is a well accepted research convention.

- Groups can be smarter than individuals - in shaping the future, we have to allow space for the future to shape itself, as group wisdom frequently finds better solutions, and allows new ways of working and being able to emerge. 
In terms of corporations, connectivity and scenarios, the experience of Battelle in turning technologies into products is worth recording [Barbera, 2001]:

\begin{abstract}
"Scenarios have become an extremely useful tool to engage and join people and their dreams within very real contexts. Everyone can understand and relate to these ideas because they've emerged from the collective, collaborative efforts between technologists and market visionaries. People become passionate about their involvement in what they've created. Scenarios are used to elicit and discover innovation as well as drive it towards realisation. Scenario creating is fuelling Battelle's innovative efforts and is right in alignment with Gordon Battelle's vision of so many years ago."
\end{abstract}

\title{
Composition
}

As previously indicated, at DIT we have been using the Prospective Through Scenarios method of strategic thinking in much of our work. This requires the assiduous shaping of a preferred future, or prospective, and the careful composition of alternative scenarios through which that vision can be created. Indeed, scenario thinking has become central to most of our studies and by far our favoured technique within the prospective methodology. It facilitates participation, stimulates the imagination, reduces inconsistency, builds a common language, structures collective thinking, avoids dogmatism and fosters a shared view and collaborative ownership. Scenario thinking, or scenario planning, is not, or course, a tool for making forecasts or predictions. The future remains as uncertain and unpredictable as ever. Rather it is a tool for better decision-making. In particular it is a decision-making tool of great power in a world where there is a growing recognition of many disparate values, aspirations and beliefs, where no single truth subsumes all others. A regulatory scientific worldview of mechanistic systems has evolved into an awareness of an uncertain world woven together by elaborate networks of information where relationships among things and between forces matter most.

Next, one hopes that an emerging wisdom will promote the cause of a responsible and relational worldview as a foundation for understanding how a collective, collaborative, coherent vision of the future might best be framed. It is here that scenarios become a vital tool for furthering dialogue among differences. Each ethical standpoint has the chance to design its own scenarios of the future embodying their respective hopes and fears within the storylines. Scenarios can help foster comprehension of, and empathy towards other peoples visions for tomorrow. Scenarios are only stories after all - not ideologies or matters of faith - but simply ways of exploring alternative possibilities. They do, however, provide a way of having more imaginative and coherent conversation about the future. And since there is more than one plausible scenario, scenario thinking and planning enables a dialogue to be conducted without winners and losers. Indeed, it has been said that [Schwartz, 2002]:

"The differences among us are the most important tools for creating a diversity of possible futures, giving real meaning to human freedom". 


\section{CHAMPIONING PROSPECTIVE THROUGH SCENARIOS}

The culture of a company and the way in which it is led are imperative to its successful functioning. Corporate culture and corporate leadership are inextricably linked. One without the other is useless. From the standpoint of culture, a company's top leaders are responsible for defining, upholding and where necessary - evolving the company's culture. Such leaders must provide direction, reason and motivation [Scott, 2001]. They must also have the ability to prioritise, guide and work within teams, explaining the vision and strategic direction to others, and galvanising their collective and collaborative action towards it. Accepting the critical need for vision, Alberto Cohen of Shell [2001] suggests two other essential qualities:

"One is 'sustainable thrust', the never-ending push that maintains momentum at any stage of the process. The other is 'dialogue', as the ability to keep open, clear and reliable channels of communications in time and space within a company."

With regard to foresighting, leaders are able to use the information developed from the programme, especially where scenarios have been employed, to help identify trends, people and technologies that may impact upon their business. Indeed, the very process of constructing scenarios requires inputs from throughout the organisation, which allows the communication and creativity between people to flow more freely, and provides the vision required for successful leadership. In fact, scenario planning, leading to the formulation of a 'prospective' can be the discipline that helps corporations gain comfort with change, but it needs championing.

Three key action areas are:

口 Commitment

- Confidence

- Catalysts

\section{Commitment}

There is little point in conducting a prospective through scenarios process for the purposes of strategic planning if decision makers at all levels of the organisation are not involved. In particular, the imprimatur of the leader of the organisation upon a scenarios exercise is of great importance, and sends a strong signal to that organisation that the project is a serious one. Just as crucial, however, is the support and participation of senior management 'down the line'. If line managers do not fully subscribe to the process, have problems in understanding the need for developing scenarios, or cannot endorse the logic supporting particular plots, then they cannot be expected to appreciate the critical implications of various scenarios, or even to know what questions they ought to ask that would link scenario content to current or future decisions. Some key lessons in respect of corporate commitment can be summarised as follows:

- Establish clear goals.

- Connect with strategic planning.

- Resolve whether the purpose is learning or planning 
- Decide who exactly the target audience is.

a Determine precisely which issues or topic the organisation is trying to understand

a Pose a pertinent strategic question.

- Remember that scenarios are not predictions.

- Involve decision-makers in the initial process.

- Take great care in scenario team selection.

- Do not underestimate the amount of work involved.

- Employ a recognisable formal method.

- Foster executive ownership of the process.

- Determine who is responsible for taking action

\section{Confidence}

Involving and committing the key stakeholders, internally and externally, is paramount in achieving a successful outcome to a prospective through scenarios exercise. Gaining their confidence, however, is paramount. A broad base through optimising connections among a variety of networks, and an inclusive approach towards all agencies and individuals who might be affected, should be sought. At the end of the day, it is about people, and their support. Again, a few key lessons can be listed:

- Foster comprehension of the purpose of the exercise.

a Agree what can be done, and what cannot.

- Aim ultimately to develop a shared vision of the future.

- Create a common language within the organisation.

a Pay attention to the 'organisation culture'.

- Recognise that there are many ways of conducting scenario planning exercises.

- Do not limit the scope of the exercise.

- Go for depth as well as breadth.

口 Undertake a pilot study if possible.

- Hold an induction or training workshop.

- Make sure the process is continuous and cumulative.

a Appreciate that 'brainstorming' is at the heart of it all.

- Make the recommendations simple, clear and relevant.

a Demonstrate the feasibility of the recommendations.

a Appreciate that there are other results as well as formal recommendations.

- Provide a proper framework for results.

- Be aware that success is hard to pinpoint.

- Recognise that corporate learning is an iterative process.

\section{Catalysts}

The process of prospective through scenarios is often more important than the product. Bringing the right people together to share their perceptions and ambitions, and enabling them to think creatively and flexibly, is frequently as valuable as the particular findings from the effort. The scale of the study, moreover, is not necessarily commensurate with the impact. Sometimes short, simple exercises can be every bit as effective as more extensive, elaborate ones. What matters is when, how, why and for 
whom they are conducted. In this, certain ingredients, actions or decisions can have a catalytic effect upon the process and its outcome. Once more, a few key lessons can be recorded:

a Find a 'champion'.

口 Include diverse interest groups and key actors.

- Take testimony from experts.

口 Introduce a few 'remarkable' people.

- Choose an experienced and appropriate facilitator.

- Use consultants prudently.

- Remember that time and timing are all-important.

- Establish links with similar activities elsewhere.

- Have an awareness of the value of 'metaphor'.

a Recognise that anecdotes and aphorisms can be helpful.

- Invoke a feeling of crisis.

- Secure the inclusion of relevant and compelling information.

a Choose evocative and germane names for the scenarios.

- Concentrate on 'pivotal uncertainties'.

- Connect the costs and benefits of the recommendations.

- Devise a set of indicators for implementation.

- Be innovative in presentation.

All the 'key lessons' linked in the sections above are more fully explored and explained elsewhere [Ratcliffe, 2003].

\section{CONCLUSION}

Whilst this paper has concentrated upon describing some of the 'grand challenges' facing corporations in the modern world, and suggesting how foresight, more preferably prospective through scenarios, can help explore, explain and enact change, there is a bigger picture of organisational transformation that calls for a futures view and appraisal. Put simply, the accent of management theory and business practice will have to shift from a preoccupation with the 'formal organisation' to focus on a kind of corporatism grounded in post-modern, disorganised capitalism. This will be characterised by discontinuity, loosely-coupled systems, synergies, and alliances, collaborative individualism, social sustainability, holism, leadership diversity and a participant-centred paradigm [Limerick, et al, op cit]. And, it will require a new philosophy, knowledge base and methodology. One which concentrates on the actor rather than the structure, and contextualisation rather that universalism. It is also one which treats the participant as researcher, promoting the role of involved individual's interpretations and explanations of subjective experience as essential for adequate strategic thinking, planning and action [ibid]. Above all, it will be a value-driven system that fosters the evolution of the socially sustainable organisation. This requires the 'proactivity' of prospective founded on the 'imagineering' of scenarios. For, to return to where we started, we can shape the future if we can first imagine it. This is the greatest challenge of all. 


\section{References}

Altherton, A. [2005]. "A Future for Small Business" Futures,

(November forthcoming)

Bazerman, M. and M. Watkins. [2004]. Predictable Surprises. Harvard Business School Press, Boston, Mass.

Cohen, A. [2001]. Quoted in Scott below.

Collier, J. and T. Fuller. [2005]. "Corporations, ethics and global futures". Futures, Vol 37, p $111-116$.

Collins, J. and J. Parra. [1996]. "Building Your Company's Vision" Harvard Business Review, Sept/Oct, p 65-77.

Economist. [2005]. “The Good Company”. Leader, January $22^{\text {nd }}$.

Ekvall, G, and Y. Tangeberg-Andersson. [1986]. "Working Climate and Creativity". Journal of Creative Behaviour, Vol 20 No. 3. [Quoted in Zeisler \& Harris below].

FOREN [2001]. A Practical Guide to Regional Foresight. European Commission, Brussels.

Fuller, T. and F. Tilley. [2005] "Corporate ethical futures”. Futures, Vol 37 p. 183 197.

Gringer, P. D. Mayes and P. McKiernan [1989]. Sharpbenders: The Secrets of Unleashing Corporate Potential. Blackwell, Oxford

Harman, F. and G. Jacobs [1985]. The Vital Difference: Unleashing the Powers of Sustained Corporate Success. AMACOM, New York.

van der Heijden, K. [1996]. The Art of Strategic Conversation. Wiley, Chichester.

van der Heijden, K. [2002]. The Sixth Sense: Accelerating Organisational Learning with Scenarios. Wiley, Chichester.

Heinzen, B. [1999]. "Why we get our forecasts wrong". Scenarios and Strategy Planning, August/September.

Irvine, J. and B. Martin. [1984]. Foresight in Science. Pinter, London.

Johansson, F. [2004]. The Medici Effect: Breakthrough Insights at the Intersection of Ideas, Concepts and Cultures. Harvard Business School Press, Boston, Mass.

Koestler, A. [1964]. The Act of Creation. MacMillan, New York. 
Limerick, D. Cunnington, B. and F. Crowther. [2002]. Managing the New Organisation. Allen \& Unwin, Australia.

Ogilvy, J. [2002]. Creating Better Futures. Oxford University Press, New York.

Peters, T. [1998]. "Facing up to the Need for a Management Revolution". California Management Review, Vol 30 No 2 p. 7-28.

Ratcliffe, J. [2002]. "Scenario Planning: Strategic Interviews and Conversations". Foresight, Vol 4, No. 1.

Ratcliffe, J. [2003] “ Scenario Planning: An Evaluation of Practice”. Futures Research Quarterly, Winter, Vol 19, No. 4.

Schwartz, P. [2002]. "Foreword". In Ogilvy cited above.

Scott, A. [2001]. "Scenario and Strategy Planning, Corporate Culture and Leadership". Scenario and Strategy Planning, October/November.

Zeisler, S, and D. Harris. "Order from Chaos". Scenario Strategy Planning, August 